УДК 662.769.21

ВОДОРОД, КАК АВТОМОБИЛЬНОЕ ТОПЛИВО

\title{
HYDROGEN AS CAR FUEL
}

Абдрахманова К. Н., Ворохобко В. В., Гареева Г. Р., Минниахметова А. А.

ФГБОУ ВПО «Уфимский государственный нефтяной технический университет», г. Уфа Российская Федерация

K. N. Abdrakhmanova, V. V. Vorokhobko, G. R. Gareeva A. A. Minniakhmetova

FSBEI HPE “Ufa State Petroleum Technological University”, Ufa, the Russian Federation

\section{e-mail: galiya.gareeva2015@yandex.ru}

Аннотация. Рост цен на энергоносители, загрязнение окружающей среды, дефицит топлива - вот причины, которые требуют разработки новых методов экономически эффективного и экологически чистого топлива из углеводородного сырья, органических отходов и воды. Водород - самый распространенный химический элемент во Вселенной. При горении водород не выделяет никаких загрязняющих атмосферу веществ, КПД электродвигателя на водородном топливе намного выше ДВС, но проблемой является дороговизна и сложность получения водорода в промышленных объемах. Он имеет широкий спектр возможности его применения в различных отраслях промышленности. Ресурсы водорода, находящегося в органическом веществе и воде, практически бесконечны. Для того чтобы использовать его как топливо, необходимо разорвать химические связи, и предотвратить рекомбинации водорода и кислорода. 
Использование последовательных химических реакций при производстве водорода довольно эффективно, но, пожалуй, не настолько известно и распространено, как электролиз воды.

Разлагать воду на водород и кислород [3] возможно при помощи процесса прямого термолиза при температуре $2500{ }^{\circ} \mathrm{C}$. Но, стоит заметить, что возможно термическое разложение воды и при более низкой температуре. Для осуществления этого используется цепочка химических реакций, выполняющих определенные функции: связывание воды, отщепление кислорода и водорода, регенерация реагентов.

Разрыв химических связей позволяет производить водород и использовать его как топливо. Это послужило причиной возникновения огромного спроса на водород, и, следовательно, потребности в увеличении производственных мощностей.

Abstract. Rising energy prices, environmental pollution, fuel shortage are important reasons for developing new cost-effective and environmentally friendly fuel from hydrocarbons, water and organic wastes. Hydrogen is the most abundant element in the world and it is used in different areas of industry. When burning hydrogen does not emit any atmospheric pollutants, efficiency of hydrogen fuel much above engine, but the problem is the high cost and complexity of producing hydrogen on an industrial scale. Hydrogen resources in water and organic matter are endless and breaking of chemical bonds allows using hydrogen as fuel. In order to use it as fuel, it is necessary to break a chemical bond, and prevent the recombination of hydrogen and oxygen. The use of sequential chemical reactions for hydrogen production is quite efficient, but perhaps not as well known and widespread as the electrolysis of water.

To decompose water into hydrogen and oxygen [3], possibly with the help of the process, direct thermolysis at a temperature of $2500{ }^{\circ} \mathrm{C}$. However, it should be noted that possible thermal decomposition of water and at a lower temperature. For this implementation uses a chain of chemical reactions that perform specific functions: the binding of water, the cleavage of oxygen and hydrogen, 
regeneration of the reagents. It makes brisk demand for hydrogen and the need to increase production capacity.

Ключевые слова: производство водорода, паровая конверсия, термоядерный синтез, монооксид углерода, электролиз воды, «тяжелая вода», «легкая вода», термическое разложение воды.

Key words: hydrogen production, steam conversion, thermonuclear fusion, carbon monoxide, water electrolysis, heavy water, water, thermal decomposition of water.

Водород имеет широкий спектр возможности его применения в химической и нефтехимической промышленности, как транспортное топливо, в металлургии и т.д. С развитием техники и науки люди все чаще задаются вопросом о создании и распространении нового более экологичного и дешевого топлива для автомобилей. Около четверти от всех выбросов в атмосферу углекислого газа производилось в результате работы разных видов транспорта. Эти выбросы пагубно сказываются на здоровье человека и на климатическом состоянии земли в целом.

В современном мире электромобили становятся все более популярными, оттесняя традиционные автомобили на топливных элементах, но, тем не менее, ученые с разных частей света предлагают использовать в качестве топлива водород, который имеет ряд преимуществ. При горении водород не выделяет никаких загрязняющих атмосферу веществ, КПД электродвигателя на водородном топливе намного выше ДВС, но проблемой является дороговизна и сложность получения водорода в промышленных объемах. Повсеместное внедрение водорода и в других отраслях, таких как промышленность, в качестве реагента, удобрения, топлива требует разработать новые методы экономически эффективного и экологически чистого производства водорода из углеводородного сырья, органических отходов и воды. Различают несколько способов производства водорода: 
- паровая конверсия;

- газификация угля;

- электролиз воды;

- пиролиз;

- биотехнологии;

- частичное окисление.

На данный момент, паровая конверсия метана является основным процессом производства водорода. Посредством этого способа производится большая часть промышленного водорода [1].

В докладе Б. Т. Плаченова и др. [2] предлагается использование способа производства водорода методом паро-углекислотной конверсии природного газа.

Это достигается за счет того, что углекислый газ смешивают с предварительно нагретыми легкими углеводородами и парами воды. Далее с целью получения синтез-газа и разделения ее на водород и монооксид углерода газовую смесь направляют в реакционную камеру для термической конверсии. Затем монооксид углерода смешивают с воздухом, полученную смесь подогревают при избыточном давлении и температуре на 50-100 ${ }^{\circ} \mathrm{C}$ ниже температуры самовоспламенения этой смеси. После принудительного воспламенения смеси и окисления монооксида углерода, производят расширение, охлаждение и отделение углекислого газа. Углекислотно-паровую конверсию проводят в реакционной камере, выполненной в виде проточного реактора, размещенного в камере горения, используя тепло при окислении монооксида углерода при повышенном давлении и температуре, находящейся в пределах 700-1500 ㄷ. За счет тепла охлаждаемых продуктов окисления монооксида углерода совершается подогрев смеси углекислого газа и воды до температуры 300-700 ${ }^{\circ} \mathrm{C}$, с последующей подачей ее в реакционную камеру углекислотно-паровой конверсии. 
Побочным эффектом паровой конверсии является углекислый газ, который также поступает в атмосферу, как при сжигании ископаемого топлива, но способ, предложенный Б. Т. Плаченовым и др. позволяет добиться повышения выхода водорода, а также сокращения выброса углекислого газа. Полученный газ следует направить на дальнейшую очистку. Схема установки представлена на рисунке 1.

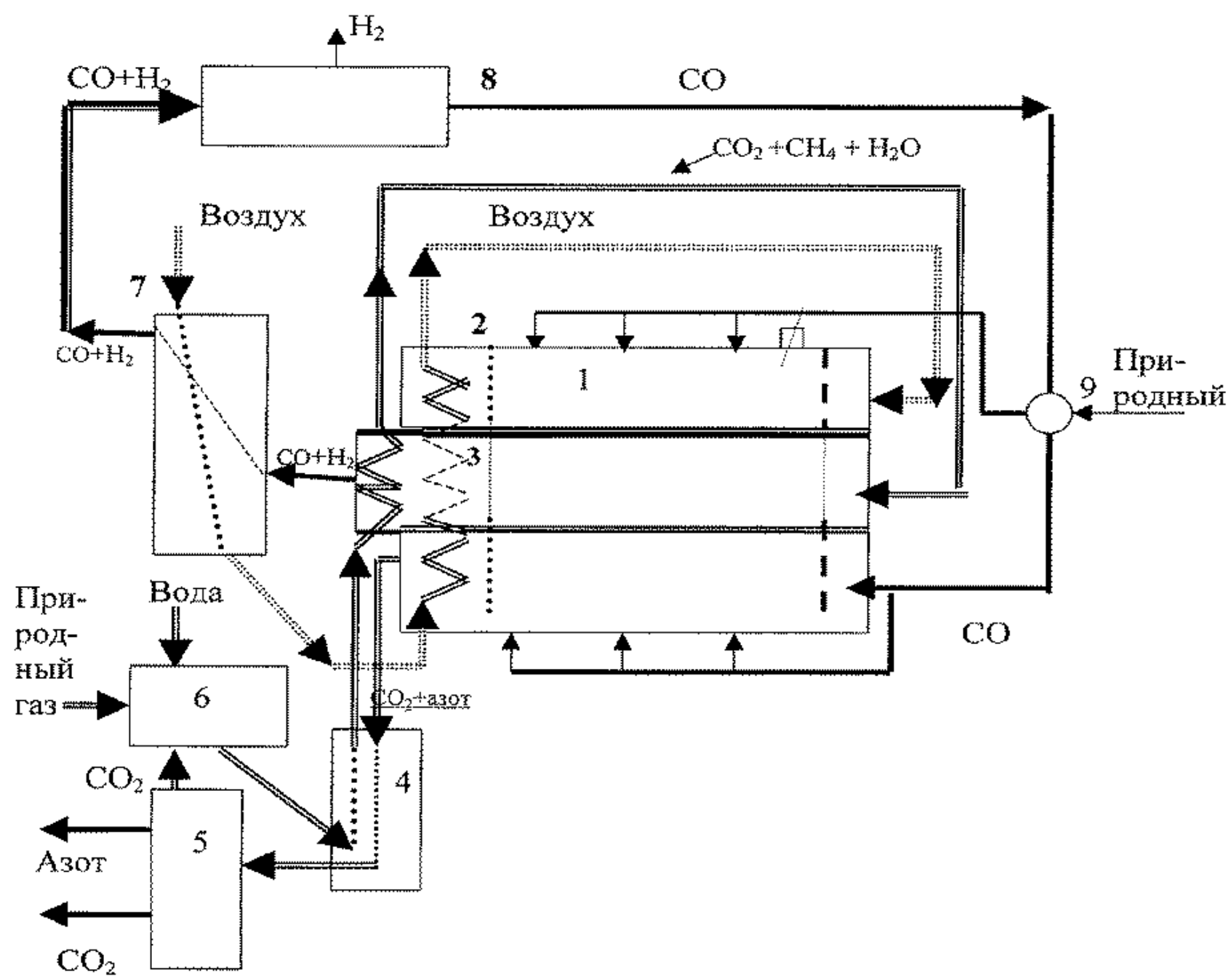

Рисунок 1. Схема установки производства водорода паровой конверсией [2]: 1 - камера горения; 2 - теплообменник; 3 - реакционная камера; 4 - теплообменник-утилизатор; 5 - блок отделения углекислого газа; 6 - смеситель; 7 - теплообменник; 8 - система разделения; 9 - клапан-переключатель

Если подойти к вопросу производства водорода с другой стороны, то можно отметить, что ресурс водорода, находящегося в органическом веществе и воде, практически бесконечны.Для того чтобы использовать его 
как топливо, необходимо разорвать химические связи, и предотвратить рекомбинации водорода и кислорода.

Разлагать воду на водород и кислород [3] возможно при помощи процесса прямого термолиза при температуре $2500{ }^{\circ} \mathrm{C}$. Но, стоит заметить, что возможно термическое разложение воды и при более низкой температуре. Для осуществления этого используется цепочка химических реакций, выполняющих определенные функции: связывание воды, отщепление кислорода и водорода, регенерация реагентов. Термохимические процессы такого типа требуют подвода тепла, при температуре в пределах $1000{ }^{\circ} \mathrm{C}$. Источником тепла при термохимическом разложении воды на составляющие является высокотемпературный реактор. В отдельных случаях, наряду с термическим воздействием, возможно использование электричества.

Исследовано большое количество сочетаний химических реакций, при которых происходит расщепление воды в замкнутом цикле на кислород и водород с поглощением тепла и электричества. На основе паровой конверсии метана подобным циклом, из воды производится примерно 50\% водорода. Довести долю водорода, получаемого из воды, до 100\% возможно путем плазменного или электрохимического восстановления метана из метанола с возвращением его в начало процесса. Основными критериями выбора, определяющего способ процесса разложения воды, являются: эффективность цикла, доступность и стоимость реагентов, термодинамические и кинетические характеристики отдельных реакций, совместимость реагентов и конструкционных материалов, безопасность процесса, экологические и экономические соображения [3].

Использование последовательных химических реакций при производстве водорода довольно эффективно, но, пожалуй, не настолько известно и распространено, как электролиз воды.

Электролиз [3] позволяет получать водород разложением воды посредством воздействия электрическим током. Данный метод дает возможность получать довольно высокую чистоту конечного продукта, и, к тому же, со- 
путствующим продуктом при получении водорода является не менее ценный в производстве кислород.

Этот способ основывается на том, что под воздействием мощного электрического тока ионы, на которые распались молекулы воды, движутся к электродам. Теряя или же приобретая на них заряд, частицы образуют новые двухатомные молекулы кислорода и водорода.

Так, например, в разработках [3] техническим результатом изобретения является получение водорода за счет разложения воды.

Согласно изобретению способ получения водорода из воды включает разложение воды под действием электрического поля с помощью водяного коаксиального конденсатора с изолированными обкладками. На эти обкладки подается высоковольтное выпрямленное напряжение импульсной формы, при этом разложение воды на кислород и водород происходит под действием резонансного электромагнитного поля, частота n-ой гармоники которого приближается к собственной частоте воды, причем энергия разложения воды складывается из тепловой и минимально расходуемой электрической энергии разложения воды.

В 1888 г. Лачинов Л. Л. [4] предложил проводить электролиз под давлением. Позже было установлено, что давление позволяет повышать температуру электролиза, вследствие чего улучшается электропроводность электролита и снижается перенапряжение.

Несмотря на все достоинства и возможности описанных выше способов получения водорода, все они имеют немаловажные недостатки - дорогостоящее производство. Поэтому, в настоящее время, большие силы брошены в разработку проекта термоядерного синтеза, который должен открыть для человечества неисчерпаемый источник энергии.

Один из вариантов получения водорода с помощью термоядерного синтеза [5] включает прохождение потока смеси «тяжелой воды» и «легкой воды» под давлением через одно или несколько отверстий диэлектрического элемента, воздействие магнитным полем на путь прохождения 
смеси и разделение ее на три потока. При этом два потока, имеющие различные по электрическому знаку и химическим свойствам ионы, электрически изолируют, ускоряют их прохождение и направляют в коллиматоры. Смесь «тяжелой воды» и «легкой воды» берут в соотношении, необходимом для управления ядерной реакцией. Устройство включает диэлектрически-стойкий к кавитационной эмиссии корпус для приема смеси. В полости корпуса установлена вставка, выполненная из диэлектрического материала, склонного к кавитационной эмиссии, которая снабжена одним или несколькими отверстиями для прохождения смеси. На пути прохождения смеси установлены магниты. В корпусе сформированы электрически изолированные друг от друга патрубки для принятия ионизированных потоков. По пути ионизированных потоков расположены управляющие электроды и контакторы, а в конце пути ионизированных потоков установлены коллиматоры с контакторами. Схема установки представлена на рисунке 2.

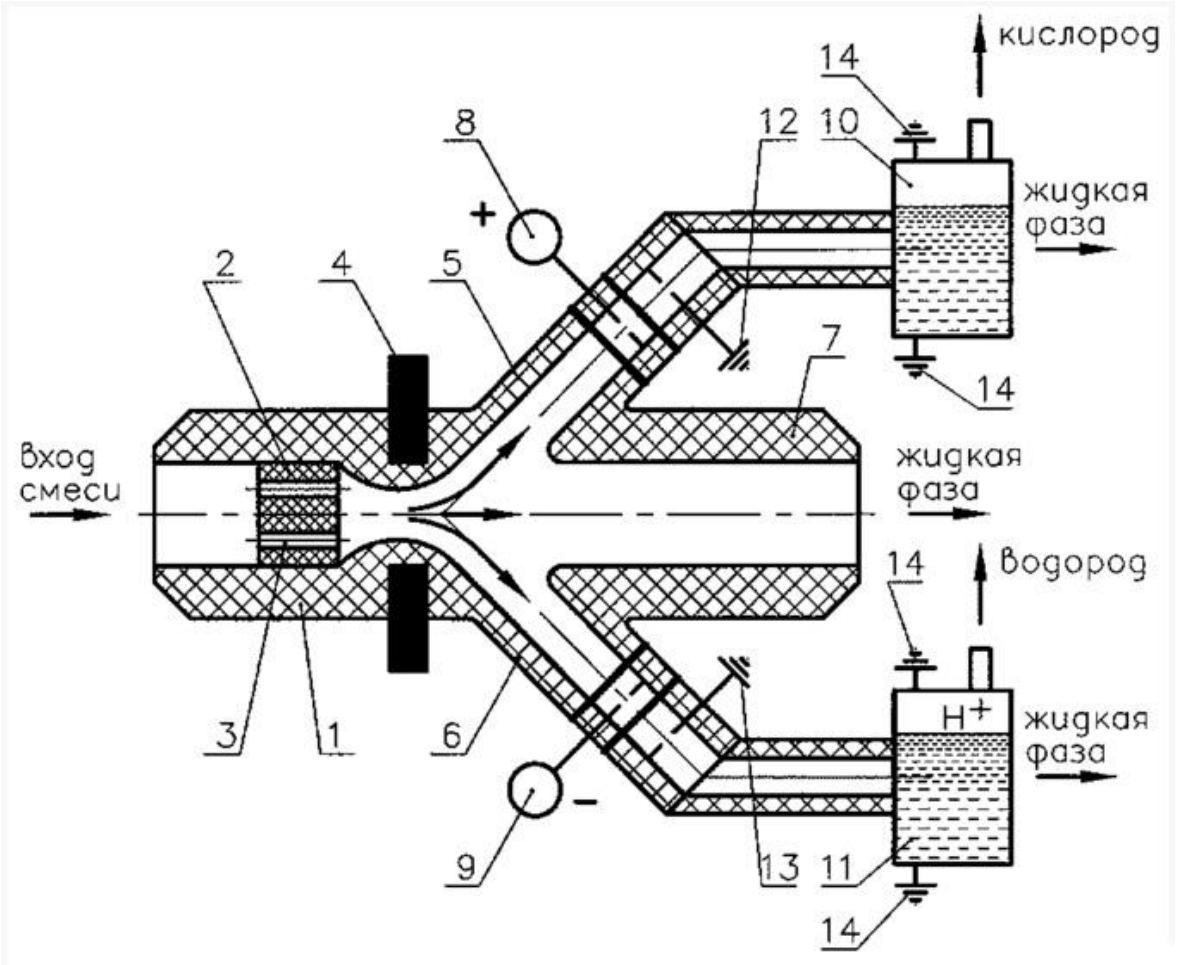

Рисунок 2. Производства водорода с помощью термоядерного синтеза [7] 1 - корпус; 2 - вставка из диэлектрического материала; 3 - отверстия; 4 - магниты; 5, 6, 7 - патрубки; 8, 9 - управляющие электроды; 10, 11 - коллиматоры; 12, 13, 14 - контакторы 
Предложенное изобретение позволяет получать водород из смеси «тяжелой воды» и «легкой воды» в количествах, достаточных для использования на практике, как в промышленности, так и в качестве топлива.

\section{Выводы}

В заключение хотелось бы отметить, что водород давно рассматривается как автомобильное топливо. Его привлекательность в этой роли обусловлена тем, что процесс превращения энергии с его участием экономически эффективен и чист с точки зрения экологии. Способы производства водорода в промышленных масштабах постоянно изучаются и улучшаются учеными во многих странах по всем миру, использование водорода как основного вида топлива имеет огромное будущее.

\section{Список используемых источников}

1 Гамбург Д. Ю. Водород. Свойства, получение, хранение, транспортирование, применение. М.: Химия, 1989. 467 с.

2 Способы производства водорода методом паро-углекислотной конверсии природного газа. Пат. 2379230 РФ №2008114670/15; заявл. 08.04.2008; опубл. 20.01.2010; Бюл. № 2.8 с.

3 Способ получения водорода из воды. Пат. РФ 2456377, МПК С25В 1/04. №2011105903/07, заявл. 18.02.2011; опубл. 20.07.2012; Бюл. № 20.7 с.

4 Электролиз под давлением URL:http://chem21.info/info/1537286/

5 Получения водорода с помощью термоядерного синтеза. Пат. РФ 2258028, МПК С25В 1/04. № 2004102538/15, заявл. 28.01.2004; опубл. 10.08.2015; Бюл. № 22. $11 \mathrm{c}$. 


\section{References}

1 Gamburg D. Yu. Vodorod. Svoistva, poluchenie, hranenie, transportirovanie, primenenie. M.: Himiya, 1989. 467 s. [in Russian].

2 Sposoby proizvodstva vodoroda metodom paro-uglekislotnoi konversii prirodnogo gaza. Pat. 2379230 RF S2. 12.04.2009. №2008114670/15; zayavl. 08.04.2008; opubl. 20.01.2010; Byul.№ 2. 8 s. [in Russian].

3 Sposob polucheniya vodoroda iz vody. Pat. RF 2456377, MPK C25B 1/04. № 2011105903/07, zayavl. 18.02.2011; opubl. 20.07.2012; Byul. № 20. 7 s. [in Russian].

4 Elektroliz pod davleniem URL:http://chem21.info/info/1537286/

5 Polucheniya vodoroda s pomosh'yu termoyadernogo sinteza. Pat. RF 2258028, MPK C25B 1/04. 2004102538/15, zayavl. 28.01.2004; opubl. 10.08.2015; Byul. 22. № 11 s. [in Russian].

\section{Сведения об авторах}

\section{About the authors}

Абдрахманова К. Н., студент группы БМР-12-01, кафедра «Технологические машины и оборудование» ФГБОУ ВПО УГНТУ, г. Уфа, Российская Федерация

K. N. Abdrakhmanova, Student BIS-12-01 the Group, of the Chair "Technological Machinery and Equipment" FSBEI HPE USPTU, Ufa, the Russian Federation

Ворохобко В. В., студент группы БМР-12-01, кафедра «Технологические машины и оборудование», ФГБОУ ВПО УГНТУ г. Уфа, Российская Федерация

V. V. Vorokhobko, Student, BIS-12-01 the Group, of the Chair "Technological Machinery and Equipment", FSBEI HPE USPTU, Ufa, the Russian Federation 
Гареева Г. Р., студент группы БМР-12-01, кафедра «Технологические машины и оборудование», ФГБОУ ВПО УГНТУ г. Уфа, Российская Федерация

G. R. Gareeva, Student, BIS-12-01 the Group, of the Chair "Technological Machinery and Equipment”, FSBEI HPE USPTU, Ufa, the Russian Federation e-mail: galiya.gareeva2015@yandex.ru

Минниахметова А. А., ассистент, кафедра «Технологические машины и оборудование», ФГБОУ ВПО УГНТУ г. Уфа, Российская Федерация

A. A. Minniakhmetova, Assistant of the Chair "Technological Machinery and Equipment", FSBEI HPE USPTU, Ufa, the Russian Federation

e-mail: lutikanna@mail.ru 